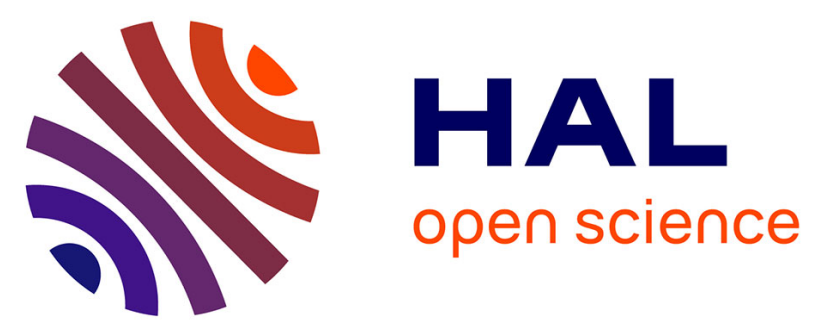

\title{
Structure and Barrier Properties of Multinanolayered Biodegradable PLA/PBSA Films: Confinement Effect via Forced Assembly Coextrusion
}

Tiphaine Messin, Nadège Follain, Alain Guinault, Cyrille Sollogoub, Valérie Gaucher, Nicolas Delpouve, Stéphane Marais

\section{To cite this version:}

Tiphaine Messin, Nadège Follain, Alain Guinault, Cyrille Sollogoub, Valérie Gaucher, et al.. Structure and Barrier Properties of Multinanolayered Biodegradable PLA/PBSA Films: Confinement Effect via Forced Assembly Coextrusion. ACS Applied Materials \& Interfaces, 2017, 9 (34), pp.29101-29112. 10.1021/acsami.7b08404 . hal-01664644

\section{HAL Id: hal-01664644 https://hal.science/hal-01664644}

Submitted on 15 Dec 2017

HAL is a multi-disciplinary open access archive for the deposit and dissemination of scientific research documents, whether they are published or not. The documents may come from teaching and research institutions in France or abroad, or from public or private research centers.
L'archive ouverte pluridisciplinaire HAL, est destinée au dépôt et à la diffusion de documents scientifiques de niveau recherche, publiés ou non, émanant des établissements d'enseignement et de recherche français ou étrangers, des laboratoires publics ou privés. 


\title{
Structure and barrier properties of multi-nanolayered biode- gradable PLA/PBSA films: confinement effect via forced as- sembly coextrusion
}

\author{
Tiphaine Messin ${ }^{1}$, Nadège Follain $^{1}{ }^{*}$, Alain Guinault ${ }^{2}$, Cyrille Sollogoub $^{2}$, Valérie Gaucher $^{3}$, Nicolas \\ Delpouve $^{4}$, Stéphane Marais ${ }^{1 *}$ \\ ${ }^{1}$ Normandie Univ, UNIROUEN Normandie, INSA Rouen, CNRS, PBS, 76000 Rouen, France \\ ${ }^{2}$ PIMM, Arts et Métiers ParisTech/CNRS/CNAM, 75013 Paris, France \\ ${ }^{3}$ Unité Matériaux et Transformations, UMR 8207 CNRS/Université Lille 1, 59655 Villeneuve d'Ascq, France \\ ${ }^{4}$ Normandie Univ, UNIROUEN Normandie, INSA Rouen, CNRS, GPM, 76000 Rouen, France
}

KEYWORDS : multilayer polymer film, coextrusion, confined crystallization, permeability, poly(lactic acid), poly(butylene succinate-co-butylene adipate), barrier properties

\begin{abstract}
Multilayer coextrusion processing was applied to produce 2049-layer film of poly(butylene succinate-co-butylene adipate) (PBSA) confined against poly(lactic acid) (PLA) using forced assembly, where the PBSA layer thickness was about 60 $\mathrm{nm}$. This unique technology allowed to process semi-crystalline PBSA as confined polymer and amorphous PLA as confining polymer in a continuous manner. The continuity of PBSA layers within the 80/20 wt\% PLA/PBSA layered films was clearly evidenced by atomic force microscopy (AFM). Similar thermal events to the reference films were revealed by thermal studies; indicating no diffusion of polymers during the melt-processing. Mechanical properties were measured for the multilayer film and the obtained results were those expected considering the fraction of each polymer, revealing the absence of delamination in the PLA/PBSA multi-nanolayer film. The confinement effect induced by PLA led to a slight orientation of the crystals, an increase of the Rigid Amorphous Fraction (RAF) in PBSA with a densification of this fraction without changing film crystallinity. These structural changes allowed to strongly improve the water vapor and gas barrier properties of the PBSA layer into the multilayer film up to two decades in the case of $\mathrm{CO}_{2}$ gas. By confining the PBSA structure in very thin and continuous layers, it was then possible to improve the barrier performances of a biodegradable system and the resulting barrier properties were successfully correlated to the effect of confinement on the microstructure and the chain segment mobility of the amorphous phase. Such investigation on these multinanolayers of PLA/PBSA with the aim of evidencing relationships between microstructure implying RAF and barrier performances has never been performed yet. Besides, gas and water permeation results have shown that the barrier improvement obtained from the multilayer was mainly due to the reduction of solubility linked to the reduction of the free volume while the tortuosity effect, as usually expected, was not really observed. This work brings new insights in the field of physico-chemical behaviors of new multilayer films made of biodegradable polyesters but also in interfacial processes due to the confinement effect induced in these multinanolayer structures obtained by the forced assembly coextrusion. This original coextrusion process was a very advantageous technique to produce eco-friendly materials with functional properties without the help of tie layer, additives, solvents, surface treatments or inorganic fillers.
\end{abstract}

\section{INTRODUCTION}

The constraints of recycling, marketing, weight and cost have led to the development of innovative solutions to replace packaging made of glass or metal with very high barriers capabilities. Over the last years there has been a growing industrial demand to develop new multifunctional organic materials of highly improved thermal, mechanical and barrier or selective properties, especially in packaging (bottles, food packaging, cosmetics, pharmaceutics...), transport (vehicles, aeronautic), building trade, energy (pipeline, tank...), and more recently in biomedical devices.
One way to make more performant materials is the use of multilayer films in which the material resistance is obtained from the layer additivity. Nowadays, the usual commercial multilayer films are made of few polymeric layers of several micrometers. It is however possible to form a multilayer structure with many nanolayers composed of alternating polymers layers by applying an innovative technique, named multilayer coextrusion process, which was developed by Dow 40 years ago $^{1,2}$ and more recently updated by Baer's group in Case Western Reserve University. ${ }^{3}$ This forced assembly layered melt-coextrusion technique consists of combining two poly- 
mers more or less compatible by forcing the two melt polymer flows in a classical 3-layers A/B/A coextrusion feedblock and and then through a series of multiplying elements in order to obtain a single film having up to thousands of alternating A and B layers with nanometric thickness. During the last decades, by applying this technique the resulting multilayer films have exhibited enhanced properties like optical, ${ }^{4}$ mechani$\mathrm{cal}^{5,6,7}$ or gas barrier properties. ${ }^{8,9,10,11}$ More recently, this technique was used to control the architecture at the micro/nanoscale of multiphase polymer systems, like nanocomposites $^{12,13}$ or triblock copolymers. ${ }^{14}$

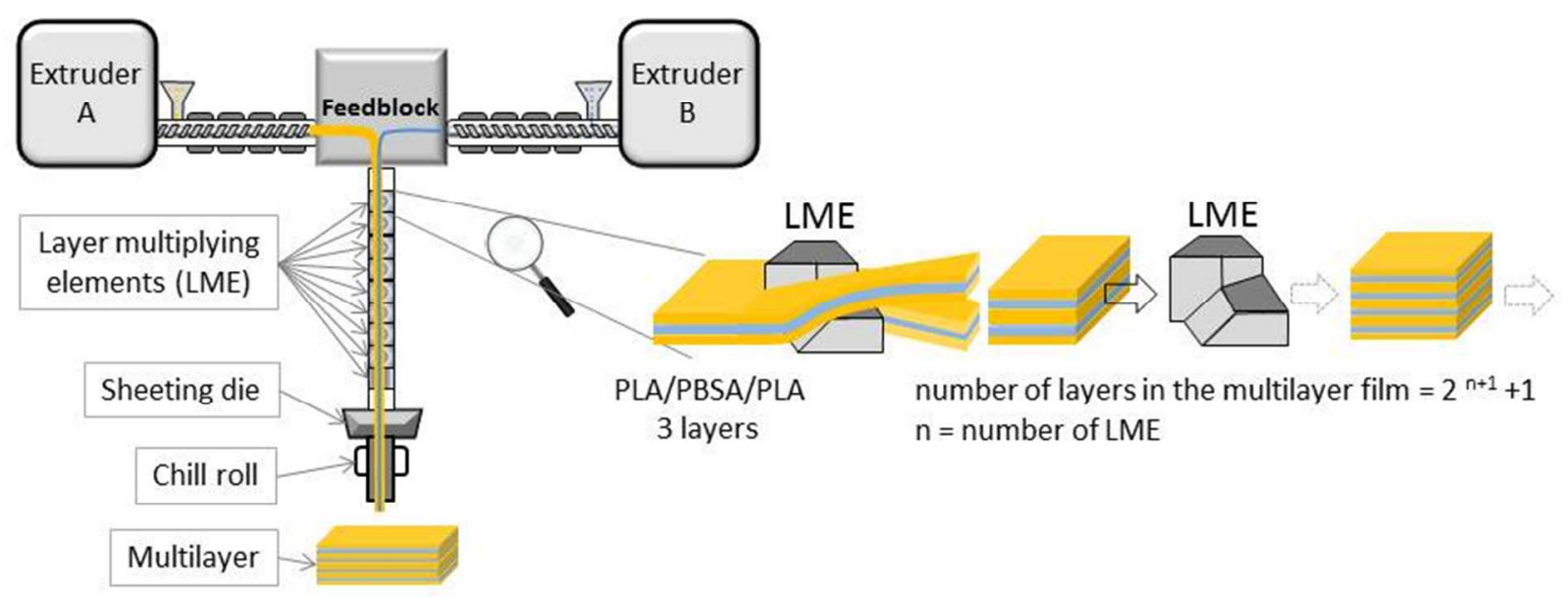

Figure 1. Schematics of the continuous two-component coextrusion process equipped with the multiplying-element device.

In some cases using semi-crystalline polymers as alternating polymers, it has been stated that this technique induces a onedimensional confined crystallization. ${ }^{15}$ Indeed, it has been reported that the spherulitic morphology can be transformed into one-dimensional crystalline lamellae due to a significant decrease of the layer thickness. It has been observed an inplane orientation of crystalline lamellae in the case of poly(ethylene oxide) (PEO) ${ }^{16}$ or poly( $\varepsilon$-caprolactone) (PCL), ${ }^{17}$ confined with an amorphous polymer (typically poly(styrene) PS). This orientation or alignment led to a substantial decrease of gas permeability with more than two orders of magnitude for confined PEO layers against PS. In some cases, to obtain this kind of crystals orientation, a biaxially stretching can be applied on the multilayer films during melt coextrusion and led to an increase of the barrier properties. ${ }^{18,19,20}$ The change in crystalline phase can accordingly have an impact on the amorphous phase through a stiffening of a part of macromolecular chains. Recently, it has been emphasized a relation between changes in barrier performances with the occurrence of a Rigid Amorphous Fraction (RAF), as an intermediate phase between crystalline and amorphous phases, ${ }^{21}$ in PBSA monolayer films, ${ }^{22}$ although not contributing to the heat capacity increment of the glass transition.

Moreover, faced with the reduction of the fossil resources and because of the environmental challenge, a great attention is focused on eco-friendly materials, especially biodegradable polymers used for packaging applications. Therefore, a wellknown alternative is the use of poly(lactic acid) (PLA) but its barrier properties remain weak compared to usual polymers like PE, PP, PET... To improve these properties, one technical way, while keeping the idea to prepare biopolyester films, is to combine PLA with another biodegradable polymer, the poly(butylene succinate-co-butylene adipate) (PBSA), which could be confined by PLA during the nano-layered coextrusion processing. Multilayer films of PLA/PBSA containing 80 $\mathrm{wt} \%$ of PLA were prepared by using a 10-multiplying elements-device to form a film with 2049 alternating layers. To our knowledge, such biodegradable system has never been performed. To have a better insight in the effect of confinement on the crystallization, PLA acting as the confining polymer was taken amorphous so that the crystallization only occurs for PBSA. For the sake of comparison, monolayer films of PLA and PBSA were also extruded to serve as reference films and to highlight the influence of the micro/nanolayers of PLA and PBSA on thermal, mechanical and barrier properties of the multilayer film.

The aim of this work was to investigate the effect of PBSA confinement against PLA on the structure and the microstructure of the multilayer film by Differential Scanning Calorimetry DSC, modulated temperature Differential Scanning Calorimetry MT-DSC, X-Ray Diffraction (WAXS) and by mechanical testing. In the present study, the resulting enhanced barrier properties of this such layered structure were characterized by probing the film through permeation kinetics by the help of various molecular probes $\left(\mathrm{N}_{2}, \mathrm{O}_{2}, \mathrm{CO}_{2}, \mathrm{H}_{2} \mathrm{O}\right)$, which differ in size as well as in interaction capacity with both polymers. In terms of barrier properties, the results obtained from water and gas permeation are new and unpublished yet. The interpretation of these results has pointed out clearly the high potential of these new biodegradable films prepared via forced assembly coextrusion and that can be considered for packaging and medical applications, PLA and PBSA being already used separately. To our knowledge, such study on these new materials made of multi-nanolayers of PLA/PBSA has never been performed yet. This experimental work has evidenced specific characteristics with enhanced barrier and mechanical properties which are found essential for industrial applications like food packaging or medical devices (suture, implant, dressing...), PLA and PBSA having also biocompatible properties.

In addition, in a context of sustainable development increasingly in demand and focused on biodegradable polymers for reducing plastic pollution, eco-friendly materials such as biopolyesters are of great interest. To date PLA remains the main 
biobased polyester used in packaging. Therefore the design of new material assembly offering enhanced properties such as multilayer PLA/PBSA is a very promising way especially as this system can be industrialized.

\section{EXPERIMENTAL SECTION}

Materials. Amorphous poly(lactic acid), ${ }^{23}$ referenced as $4060 \mathrm{D}$ grade $\left(\mathrm{L} / \mathrm{D}\right.$ isomer ratio of $88: 12, \mathrm{Tg}=55^{\circ} \mathrm{C}, \mathrm{Mw}=$ $113,6 \mathrm{~kg} / \mathrm{mol}$ ), ${ }^{24}$ was supplied by Resinex (France). Semicrystalline poly(butylene succinate-co-butylene adipate) PBSA $\left(\mathrm{T}_{\mathrm{g}}=-43^{\circ} \mathrm{C}, \mathrm{T}_{\mathrm{m}}=88{ }^{\circ} \mathrm{C}, \mathrm{M}_{\mathrm{w}}=150 \mathrm{~kg} / \mathrm{mol}\right)$, referenced as PBE001, was obtained from NaturePlast (France) with 20 mol\% of Butylene Adipate units. Before multilayer coextrusion process, the PLA and PBSA pellets were dried under vacuum at $60{ }^{\circ} \mathrm{C}$ for $12 \mathrm{~h}$ to eliminate residual moisture. The temperature of $170^{\circ} \mathrm{C}$ was chosen as the extrusion temperature according to the viscosities of the PLA and of PBSA polymers. They were found to be equal to 5165 and $2380 \mathrm{~Pa}$.s, respectively, at this temperature and at the same shear rate as processing conditions (1-10 $\left.\mathrm{s}^{-1}\right)$, inducing a viscosity rate of 2 , which ensures a reasonable viscosity match in the feedblock between both polymers.

Films preparation. The PLA and PBSA pellets were loaded into two separate single-screw extruders (a $30 \mathrm{~mm}$ screw diameter with a screw length to diameter ratio of $33 \mathrm{D}$ (30/33D) Mapre extruder at $26 \mathrm{rpm}$ with a $165 / 180 / 180 / 190 / 190 / 190{ }^{\circ} \mathrm{C}$ temperature profile for PLA and a 20/20D Scamex extruder at $26 \mathrm{rpm}$ with a $120 / 150 / 150 / 160 / 170{ }^{\circ} \mathrm{C}$ temperature profile for PBSA) and the two melt flows converged in a 3-layer $(\mathrm{A} / \mathrm{B} / \mathrm{A})$ feedblock for coextrusion process with a total flow fixed at $5 \mathrm{~kg} / \mathrm{h}$. The proportion of the multilayer is $80 \mathrm{wt} \%$ of PLA and $20 \mathrm{wt} \%$ of PBSA. The resulting melt flow was sent through 10 layer multiplying elements at $170{ }^{\circ} \mathrm{C}$, as shown in Figure 1, each of them cutting vertically the melt flow into two parts which were thereafter superposed and compressed. At the end of the multilayer coextrusion process, the temperatures of flat die and the chill roll were at $170{ }^{\circ} \mathrm{C}$ and $40{ }^{\circ} \mathrm{C}$, respectively. The total film thickness was of $300 \mu \mathrm{m}$ at a constant $80 / 20$ ratio of PLA/PBSA, with theoretically 2049 layers meaning that the PBSA layers thickness was approximately of $60 \mathrm{~nm}$. Additionally, in sake of comparison, the monolayer films of PLA and PBSA were extruded using a classical single-screw extruder, without a feedblock and multiplying-elements device, under similar processing conditions. The final thickness of the films was approximately $200 \mu \mathrm{m}$. The films were stored under vacuum with $\mathrm{P}_{2} \mathrm{O}_{5}$ at room temperature before characterization.

Structural characterization. Morphological characterization. In order to investigate the layered structure, films were cut perpendicular to the plane of the film using an ultramicrotome (LKB BROMMA 2088 Ultratome) at room temperature with a diamond knife. The obtained smooth cross-section was imaged under ambient conditions by Atomic Force Microscopy (AFM) using a Veeco Nanoscope V in tapping mode.

Wide Angle X-ray Scattering (WAXS) experiments were performed using a Xeuss 2.0 instrument from Xenocs. This SAXS/WAXS laboratory beamline is composed of a GeniX3D $\mathrm{Cu}$ Ultra Low Divergence microsource operated at $30 \mathrm{kV}$ and
$0.30 \mathrm{~mA}$. The $\mathrm{Cu}-\mathrm{K} \alpha$ radiation $(\lambda=1.54 \AA)$ is collimated with a FOX3D mirror and two pairs of Scatterless slits 2.0. Through-view and edge-views 2-D patterns were recorded on a Pilatus $200 \mathrm{~K}$ detector. Radial intensity profiles $\mathrm{I}(2 \theta)$ are obtained by azimuthal integration of the 2D-patterns using FIT2D software. Quantitative analyses have been performed over the $2 \theta$ range $5^{\circ}<2 \theta<42^{\circ}$ using PeakFit software. For characterizing the crystal index, the average diffractogramm is then calculated from normalized radial intensity profiles $\mathrm{I}(2 \theta)$ recorded in the three principal directions of film. All scattering peaks and amorphous halos are fitted assuming Pearson VII. For PBSA, the assignment of the scattering peaks was based on previous results. ${ }^{25}$ The weight fraction of the crystalline phase $X_{c}$ is determined from the ratio of the specific scattering contribution of the crystal phase to the total scattering area. In the case of multilayer films, the crystal content of PBSA is calculated considering the weight fraction of the polymer in the multilayer system.

Thermal properties. Thermal analyses of the monolayer and multilayer films were performed in order to determine the degradation profile and the corresponding temperature by Thermal Gravimetric Analysis (TGA), and to highlight changes in crystallinity and the characteristic temperatures by Differential Scanning Calorimetry (DSC). TGA analyses were conducted on a Q500 TGA from TA Instruments with a heating rate of $10{ }^{\circ} \mathrm{C} / \mathrm{min}$ from 30 to $600{ }^{\circ} \mathrm{C}$ under nitrogen atmosphere. The degradation temperature $\left(\mathrm{T}_{\mathrm{deg}}\right)$ also expressed as $\mathrm{T}_{\text {onset }}$, was determined when losing $5 \mathrm{wt} \%$ of the sample. DSC and MT-DSC analyses were performed with a DSC Q2000 from TA Instruments. DSC measurements were conducted on 6-7 mg of sample placed in an aluminum pan at a heating/cooling rate of $10^{\circ} \mathrm{C} / \mathrm{min}$ from -60 to $200{ }^{\circ} \mathrm{C}$. In order to well separate the different thermal events and also to determine the Rigid Amorphous Fraction (RAF) and the Mobile Amorphous Fraction (MAF), MT-DSC measurements in "Heat-Only" mode were carried out on 2-3 mg of sample from -90 to $200{ }^{\circ} \mathrm{C}$ with the following parameters: $\pm 0.21{ }^{\circ} \mathrm{C}$ for the oscillation amplitude, $80 \mathrm{~s}$ for the oscillation period and $1^{\circ} \mathrm{C} \cdot \mathrm{min}^{-1}$ for the heating rate. The degree of crystallinity, $X_{c}$, was determined by the following equation:

$$
X_{c}(\%)=\frac{\Delta H_{m}-\Delta H_{c}}{\Delta H_{m}^{0}} * 100
$$

where $\Delta H_{m}$ is the melting enthalpy, $\Delta H_{c}$ is the enthalpy of crystallization and $\Delta H_{m}^{0}$ is the melting enthalpy of a $100 \%$ theoretical crystalline polymer. For the PBSA, $\Delta H_{m}^{0}$ is equal to $113.4 \mathrm{~J} / \mathrm{g}$. ${ }^{26}$

The MAF, noted $X_{m a}$, was calculated from the glass transition by:

$$
X_{m a}(\%)=\frac{\Delta C_{p}}{\Delta C_{p}^{0}} * 100
$$

where $\Delta C_{p}$ is the specific heat capacity of PBSA and $\Delta C_{p}^{0}$ is the specific heat capacity for a $100 \%$ amorphous polymer. The $\Delta C_{p}^{0}$, equal to $0.614 \mathrm{~J}_{\mathrm{g}} \mathrm{g}^{-1} \cdot{ }^{\circ} \mathrm{C}^{-1}$, was previously determined by Bandyopadhyay et al. ${ }^{27}$

The RAF, noted $X_{r a}$, was deduced by:

$$
X_{r a}(\%)=100-\left(X_{c}+X_{m a}\right)
$$

Uniaxial mechanical test. Mechanical tests were performed on an Instron 5543 traction machine at room temperature with 
a $500 \mathrm{~N}$ load cell at a crosshead speed of $25 \mathrm{~mm} / \mathrm{min}$. The samples with $30 \mathrm{~mm}$ in length and $4 \mathrm{~mm}$ in width were prepared. A minimum of tens specimens per film were tested. The average value for the mechanical parameters, tensile strength, Young's modulus and elongation, were calculated from the corresponding stress-strain curves.

Transport properties. Gas permeation. Gas permeation measurements based on "time-lag" method were performed at $25{ }^{\circ} \mathrm{C}$ with a home-made apparatus ${ }^{28}$ which is constituted by a permeation cell containing the film placed between the upstream and the downstream compartments. After a drying step under vacuum for $15 \mathrm{~h}$, the tested gas $\left(\mathrm{N}_{2}, \mathrm{O}_{2}\right.$, or $\left.\mathrm{CO}_{2}\right)$ was introduced at 4 bars into the upstream compartment, while a pressure sensor recorded the increasing of pressure in the downstream compartment. The permeability coefficient, $P$, usually expressed in Barrer (1 Barrer $=10^{-10} \mathrm{~cm}_{\text {(STP) }}^{3} \mathrm{~cm} \mathrm{~cm}$ $\left.\mathrm{s}^{-1} \mathrm{cmHg}^{-1}\right)$, was determined considering the gas pressure passed through the film at the steady state of permeation process, according to:

$$
P=\frac{J s t * L}{\Delta p}
$$

where Jst is the stationary flux, $L$ is the film's thickness and $\Delta p$ is the difference of pressure between the upstream and the downstream compartments of the permeation cell.

The stationary flux, Jst, was determined from the slope $\alpha$ of the kinetic curve at long time:

$$
J s t=\frac{\alpha * V}{A * R * T}
$$

with $V$ is the volume of the downstream compartment, $A$ is the surface of film exposed to gas, $R$ is the ideal gas constant and $T$ is the experimental temperature.

By assuming no plasticization effect is induced by the diffusing gas molecules, the diffusion coefficient $D$ can be calculated as follows:

$$
D=\frac{L^{2}}{6 * t_{l}}
$$

where $t_{l}$ represents the time called "time-lag" which was determined from the intercept of the asymptotic straight line of the stationary flux with the time axis.

Then the solubility coefficient $S$ of diffusing gas molecules in the film can be deduced from:

$$
S=\frac{P}{D}
$$

To predict the permeability coefficient of a polymer when involved into a multilayered structure. ${ }^{10,29,30,31}$ and also to directly compare with the experimental values, the mathematical equation resulting to the well-known series model was applied according to:

$$
\frac{1}{P_{\mathrm{PLA} / \mathrm{PBSA}}}=\frac{\varphi_{\mathrm{PLA}}}{P_{\mathrm{PLA}}}+\frac{\varphi_{\mathrm{PBSA}}}{P_{\mathrm{PBSA}}}
$$

with $\varphi$ is the volume fraction of the polymer into the multilayer film and $P$ is the permeability coefficient of the corresponding monolayer film. To calculate the volume fraction, we have considered the density values measured at $25^{\circ} \mathrm{C}$ and which were 1.21 and 1.22 for PLA and PBSA; respectively. These values are close to those given by suppliers (PLA: 1.24 from NatureWorks-Resinex, PBSA: 1.23 from NaturePlast).

Also, we have prepared a PLA/PBSA blend film with the same composition (PLA/PBSA 80:20) as for the multilayer film. In both cases, we have obtained the same density 1.24 , meaning that at the macroscopic scale, the confinement has no effect on the density.

Water permeation. Water permeation measurements were performed at $25{ }^{\circ} \mathrm{C}$ using a lab-built device. The permeation cell was composed of an upside and a downside compartments separated by the tested film and swept by dry nitrogen until a low constant dew point temperature $\left(-70^{\circ} \mathrm{C}\right)$ was reached and monitored by a chilled mirror hygrometer $\left(\right.$ Elcowa ${ }^{\circledR}$, France, General Eastern Instruments). Then, the upstream part of the cell was filled with liquid water (milli Q) and the water permeation flux was measured using the rising dew point temperature as a function of time. At the stationary state, the permeation flux, Jst, is directly proportional to the permeability coefficient $P$ (expressed in Barrer) according to equation 4 . In the case of water permeation, $\Delta p$ is the difference of water vapor pressure between the upstream and the downstream compartments of the permeation cell.

In the case of vapors such as water, it is usually observed a plasticization phenomenon which leads to increase the free volume. This well-known behavior, considered as a Fickian process of type $\mathrm{B},{ }^{32}$ is usually fitted from an exponential law of diffusion according to:

$$
D=D_{0} * e^{\gamma \cdot C}
$$

where $D_{0}$ is the diffusion coefficient when the permeant concentration is close to $0, \gamma$ is the plasticization factor and $C$ is the local concentration of the permeant molecules.

At the stationary state, when $\mathrm{C}=\mathrm{Ceq}$, the maximum coefficient diffusion $D_{M}$ can be determined from:

$$
D_{M}=D_{0} * e^{\gamma \cdot C_{e q}}
$$

where $\gamma \cdot C_{e q}$ is the plasticization coefficient. 


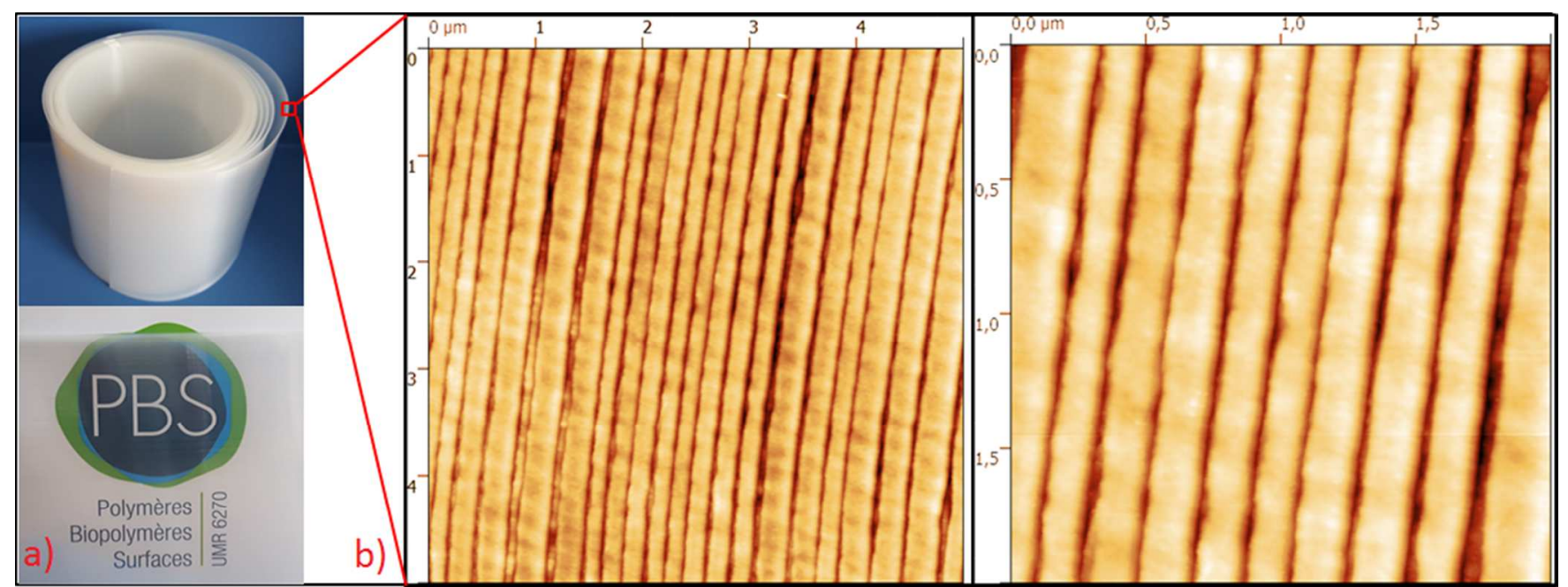

Figure 2. a) Photography of the PLA/PBSA multilayer film to highlight its homogeneity and its transparency and b) AFM images of the multilayer film of 80/20 PLA/PBSA with PLA in light and PBSA in dark.

\section{RESULTS AND DISCUSSION}

As previously reported, ${ }^{16,17,31,33}$ the barrier properties of a polymer film are usually strongly affected by the morphology developed during the film-forming process. Therfore, the elaboration of a multilayer structure using the layermultiplying coextrusion process could be a way of obtaining a certain orientation of polymer chains in the extrusion direction, which can accordingly hinder the transfer of permeants. ${ }^{22}$ Therefore the structural and morphological analyses were carried out to verify the possible change in crystallinity and crystal orientation. In the present work, the monolayer films of PLA and PBSA served as reference films in sake of comparison to the 2049-multilayer film composed of PLA/PBSA $(80 / 20 \mathrm{wt} \%)$.

Structure and morphology. From AFM observation taken on the cross-section of the films, i.e. in the extrusion direction (Figure 2), it can be observed the existence of continuous and homogeneous PBSA layers within the multilayer film. The average thickness of the PBSA layers measured from the AFM phase images following the method described in Bironeau et al. $^{34}$ varies from 50 to $70 \mathrm{~nm}$, as expected. The layer integrity is maintained within all the film. In addition, the multilayer film is viewed as a transparent film (Figure 2a), meaning that the transparence is maintained after the formation of 2049 layers of alternating polymers. Indeed, to quantify the transparency, PLA, PBSA and PLA/PBSA multilayer films have been analyzed by using the UV-Visible spectrophotometer Cary 100 Bio (Varian). The measurements have been performed at $\lambda=600 \mathrm{~nm}$ and at three different zones of all the films having the same thickness. The mean values obtained in absorbance were $0.101 \pm 0.006 ; 2.0 \pm 0.1$ and $0.52 \pm 0.02$ for PLA, PBSA and PLA/PBSA films, respectively. The low values of PLA and PLA/PBSA which are relatively close highlight that PLA/PBSA multilayer keep a quite good transparency (and as shown from images of Figure 2).
The WAXS patterns recorded on the face and on the cross section for each film are presented on Figure 3. The PLA film is represented by one broad halo, characteristic of an amorphous structure. The PBSA film exhibits two diffraction rings, indicative of the presence of a crystalline phase. Concerning the multilayer film of PLA/PBSA, both amorphous and crystalline phases are detected. As regard the chain orientation, while monolayer films exhibits rather isotropic structure, a slight crystal orientation is evidenced in the case of PLA/PBSA on both transverse and extrusion view patterns. This result may be surprising considering that in some previous works $9,16,17,33$ on multilayer films, an in-plane crystals is reported in confined polymer layer. The process conditions may be considered to explain this result. In the present study, the fact that the PBSA layers thickness was close to $60 \mathrm{~nm}$ seems to be not sufficient to force crystal alignment. 


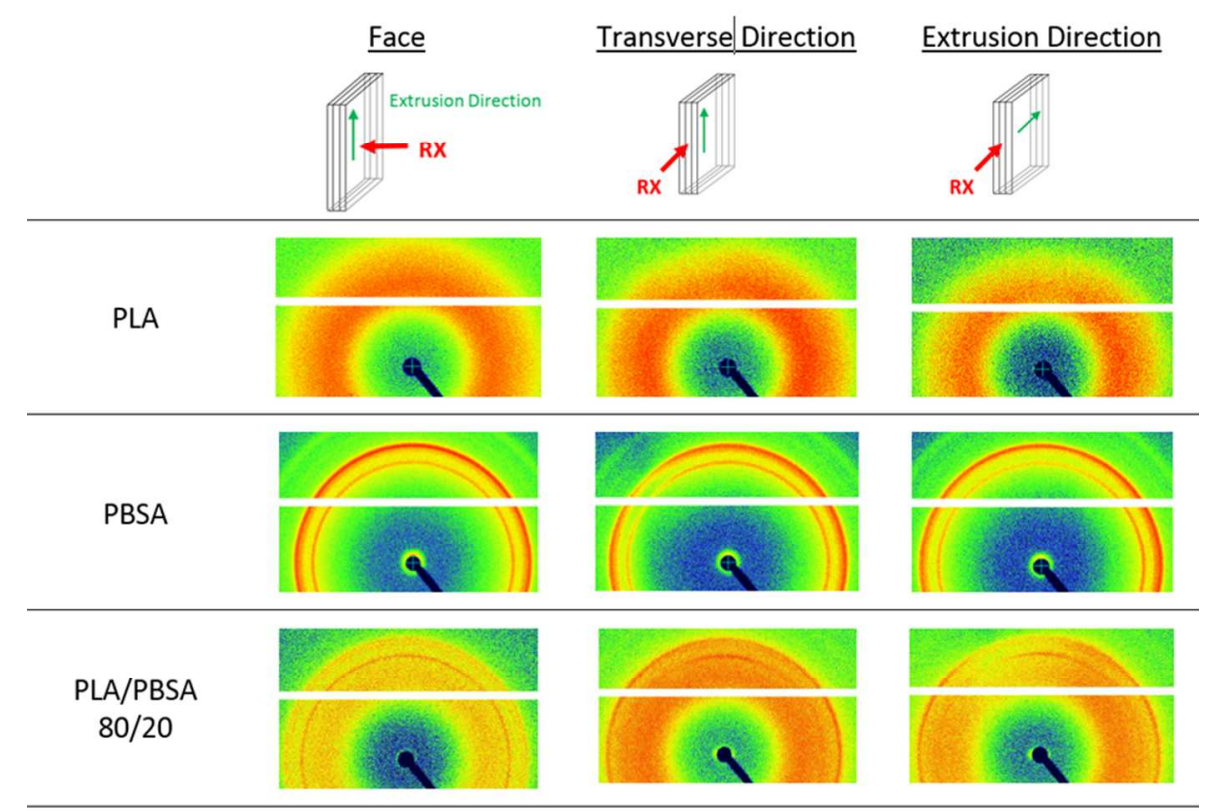

Figure 3. WAXS patterns for the monolayer films of PLA and PBSA and the multilayer film of PLA/PBSA (80/20) performed in the film face, in the transverse direction (TD) and in the extrusion direction (ED).

The average WAXS diffractograms of the monolayer films of PLA and PBSA, and of the multilayer film of PLA/PBSA are presented in Figure 4. The simulated PLA/PBSA film diffractogram is calculated considering the diffractogram and the ratio of each pure component. The good agreement between the experimental and calculated profiles suggests that the structures of both polymers are similar in monolayer and multilayer films, especially the crystal content of PBSA. To calculate the degree of crystallinity associated with the PBSA layers into the multilayer film of PLA/PBSA, the crystalline contribution was extracted from the WAXS diffractogram (considering the PBSA weight fraction) and the resulting profile (Figure $5 b$ ) is compared to that of the monolayer film of PBSA (Figure 5a). As shown in Figure 5, the diffraction planes are similar with a degree of crystallinity found to be equal to $46 \%$ for the PBSA and $42 \%$ for the PBSA under multilayer form. Note that this result is consistent with the good agreement between the experimental diffractogram and the simulated one, the latter being calculated considering the diffractogram and the ratio of each pure component.

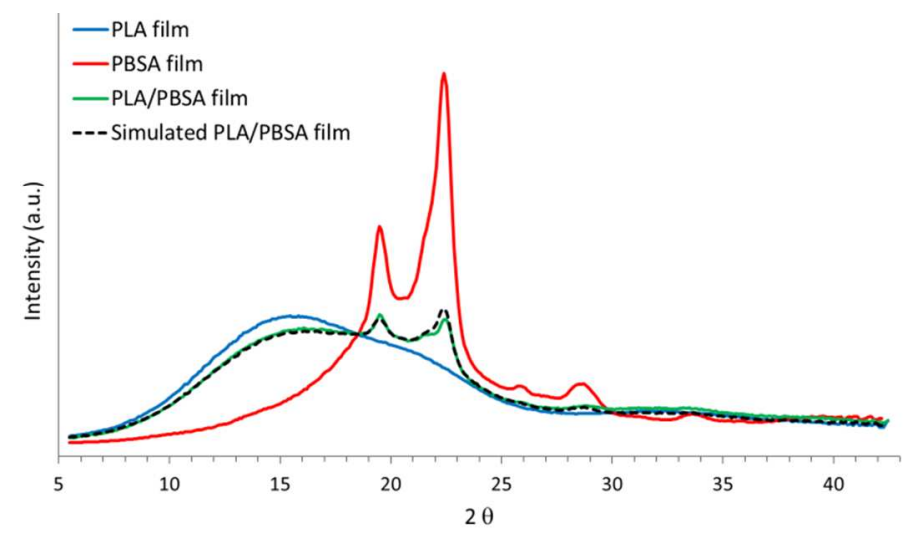

Figure 4. WAXS diffractograms for the monolayer film of PLA, the monolayer film of PBSA and the multilayer film of PLA/PBSA. 


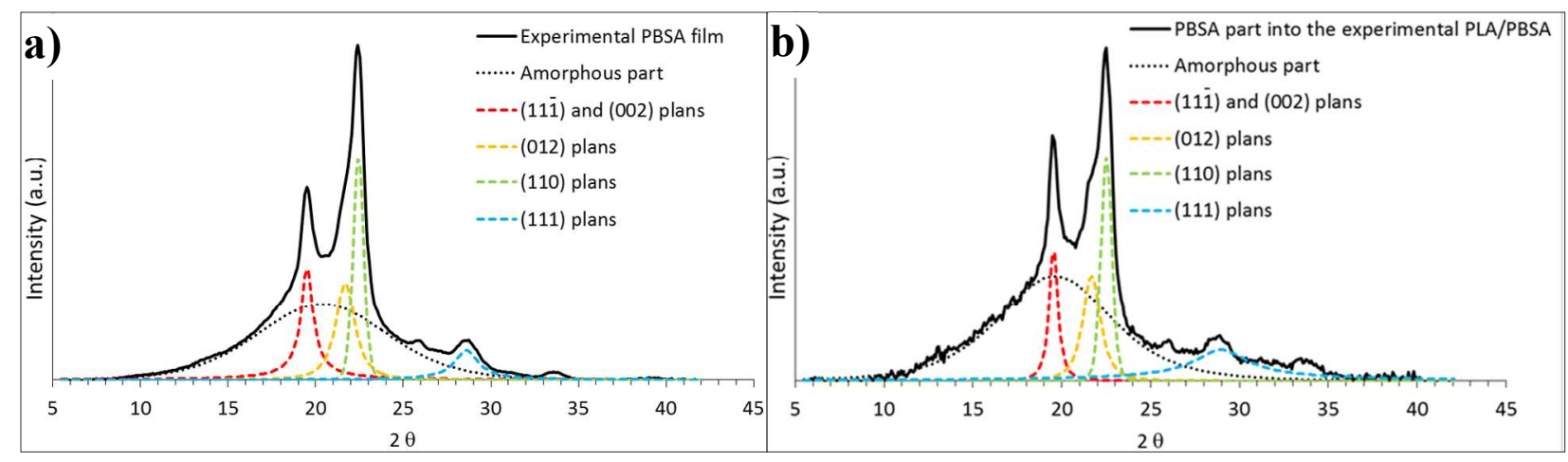

Figure 5. Deconvolution of WAXS diffractogramms presenting the amorphous halo and diffraction planes for a) the monolayer film of PBSA and $b$ ) the PBSA part into the multilayer film.

Table 1. Thermal properties for the monolayer films of PLA and PBSA and the multilayer film of PLA/PBSA (80/20).

\begin{tabular}{|c|c|c|c|c|c|c|c|c|c|}
\hline & \multicolumn{4}{|c|}{ Classical DSC } & \multirow{2}{*}{$\begin{array}{c}\text { TGA } \\
\mathrm{T}_{\text {deg }} \\
\left({ }^{\circ} \mathrm{C}\right)\end{array}$} & \multicolumn{4}{|c|}{ MT-DSC } \\
\hline & $\begin{array}{l}\mathrm{T}_{\mathrm{g} \text { PBSA }} \\
\left({ }^{\circ} \mathrm{C}\right)\end{array}$ & $\begin{array}{c}\mathrm{T}_{\mathrm{g} \text { PLA }} \\
\left({ }^{\circ} \mathrm{C}\right)\end{array}$ & $\begin{array}{c}\mathrm{T}_{\mathrm{c} \text { PBSA }}\left({ }^{\circ} \mathrm{C}\right) \\
\text { (heat) }\end{array}$ & $\begin{array}{c}\mathrm{T}_{\mathrm{m} \text { PBSA }} \\
\left({ }^{\circ} \mathrm{C}\right)\end{array}$ & & $\begin{array}{c}\Delta \mathrm{C}_{\mathrm{pPBSA}} \\
\left(\mathrm{J} \cdot \mathrm{g}^{-1} \cdot{ }^{\circ} \mathrm{C}^{-1}\right)\end{array}$ & $\begin{array}{c}\Delta \mathrm{C}_{\mathrm{pPLA}} \\
\left(\mathrm{J} \cdot \mathrm{g}^{-1} \cdot{ }^{\circ} \mathrm{C}^{-1}\right)\end{array}$ & $\begin{array}{c}X_{\text {c PBSA }} \\
(\%)\end{array}$ & RAF (\%) \\
\hline PLA monolayer & - & 55 & - & - & 328 & - & - & - & - \\
\hline PBSA monolayer & -46 & - & 67 & 90 & 349 & 0.33 & - & 38 & $9 \pm 4$ \\
\hline $\begin{array}{c}\text { PLA/PBSA } \\
\text { multilayer }\end{array}$ & -46 & 53 & 71 & 91 & 325 & $0.25^{*}$ & $0.50^{*}$ & 40 & $21 \pm 4$ \\
\hline
\end{tabular}

${ }^{*}$ values of $\Delta \mathrm{C}_{\mathrm{p}}$ are calculated after normalization to the PBSA amount for the first glass transition and after normalization to the PLA amount for the second glass transition.

Thermal and mechanical studies. The characteristic temperatures (glass transition temperature, $\mathrm{T}_{\mathrm{g}}$, crystallization temperatures, $\mathrm{T}_{\mathrm{c}}$, melting temperature, $\mathrm{T}_{\mathrm{m}}$ ) measured from the first heat cycle of DSC analyses are gathered in Table 1 . The degree of crystallinity is accordingly calculated. In addition, the degradation temperature measured by TGA analysis is added into the Table 1. The corresponding DSC thermograms are plotted in Figure 6. Although the second heat cycle in DSC is usually considered due to the erasure of the thermal history of the material, the thermal events are calculated from the first heat cycle because the material is assumed to be in the same thermal and structural states when analyzing by permeation measurements.

For the PLA polymer, the glass transition and degradation temperatures are in good agreement with those reported in the literature for an amorphous PLA. ${ }^{23}$ Similar comment can be exposed for the PBSA polymer. ${ }^{26,35}$ The endothermic event for the PBSA polymer detected around $35^{\circ} \mathrm{C}$, as already observed, ${ }^{36}$ is related to the melting of small and imperfect polymer crystals. ${ }^{37}$ In addition, an exothermic event around $67^{\circ} \mathrm{C}$ relative to a cold crystallization is observed just before the main melting peak at $90{ }^{\circ} \mathrm{C}$, as reported. ${ }^{38}$ As the melting temperatures of the monolayer film of PBSA and the multilayer film matched, one can state that the crystalline lamellae sizes are close accordingly.

As summarized in Table 1, the multilayer film of PLA/PBSA has the same characteristic temperatures as the monolayer films of PLA and PBSA.

One possible explanation for the lower $T_{\text {deg }}$ of PLA/PBSA multilayer can be related with the elaboration of the films. For those films, the layer multiplying device increases substantially the residence time of the polymers in the process, which may induce consequently a higher degradation. Besides the multiplication of interfaces may favor degradation as interfaces can play the role of domains of preferential attack during thermal degradation. However, even if some degradation can occur it must be also considered that the difference in $T_{\text {deg }}$ between PLA/PBSA multilayer film (containing in majority PLA) and PLA is relatively low $\left(3^{\circ} \mathrm{C}\right)$ taking into account the measurement errors.

It appears not possible to separate the PBSA crystallization from the PLA glass transition phenomenon due to a localization in the same temperature range. This can be bypassed by using MT-DSC measurements, which separate the glass transi- 
tion phenomenon observed in the reversible heat flow signal from the other kinetic events, like the PBSA crystallization, observed in the non-reversible heat flow signal (Figure 7).

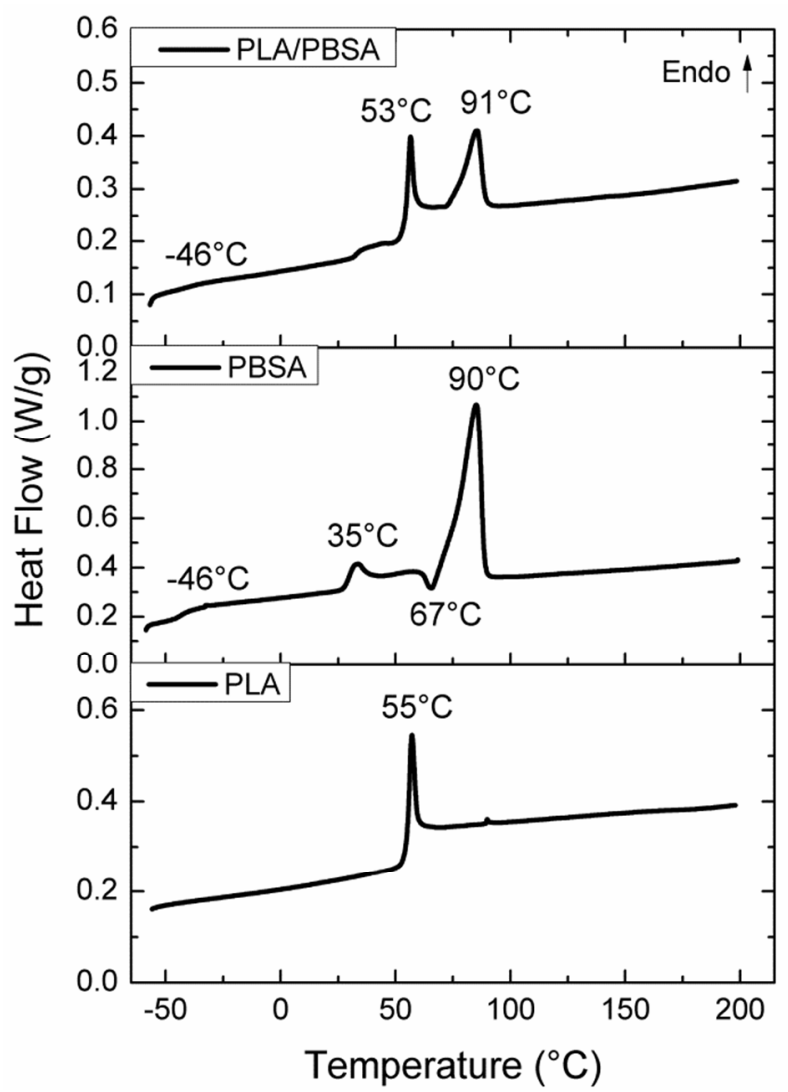

Figure 6. First-heat DSC thermograms for the monolayer films of PLA and PBSA and the multilayer film of PLA/PBSA (80/20).

Furthermore, the MT-DSC is a powerful technique to accurately measure the PBSA glass transition temperature, difficult to detect by classical DSC measurements due to the small proportion of PBSA $(20 \mathrm{wt} \%)$ within the multilayer film of PLA/PBSA. The MT-DSC was also used to well determine the $\Delta \mathrm{C}_{\mathrm{p}}$ of PBSA by means of a measurement with a low heating rate $\left(1{ }^{\circ} \mathrm{C} / \mathrm{min}\right)$ in order to highly improve the resolution.

MT-DSC reversing and non-reversing heat flow curves for PBSA monolayer are given in Supporting Information (S1).

As shown in Figure 7, the different thermal events were well separated and attributed. The values measured for the multilayer film merged well with the values of the reference films, indicating any polymer interdiffusion phenomenon between the two immiscible polymers during the melt coextrusion processing.

The Rigid Amorphous Fraction, RAF, of PBSA was then calculated according to Equation 3 and is found to be equal to $9 \%$ and $21 \%$ in the case of the monolayer film and the multilayer film, respectively. (Supporting Information S2)
This significant increase in local rigidity, probably located at the interface between the crystals and the amorphous chains, can be the result of the confinement of the PBSA layers induced by the PLA layers during forced assembly by multilayer coextrusion. The heat capacity step of PLA in the multilayer gives a value equals to $0.50 \mathrm{~J} \mathrm{~g}^{-1} \mathrm{~K}^{-1}$, after normalization to PLA content. This is consistent with the value of $\Delta \mathrm{Cp}$ obtained for neat PLA. ${ }^{50}$ It is quite reasonable to assume that PLA behaves similarly in mono- or multilayers.

The mechanical properties, gathered in Table 2, are in good agreement with those reported in the literature for $\mathrm{PLA}^{39,40}$ and PBSA $^{35,41,42}$ polymers (curves in Supporting Information S3). However, it can be noted that the average elongation at break $(1360 \%)$ for PBSA does not totally correspond to those given in the literature (ranging from 35 to $1000 \%$ ) but clearly remains in the same order of magnitude for the highest values.
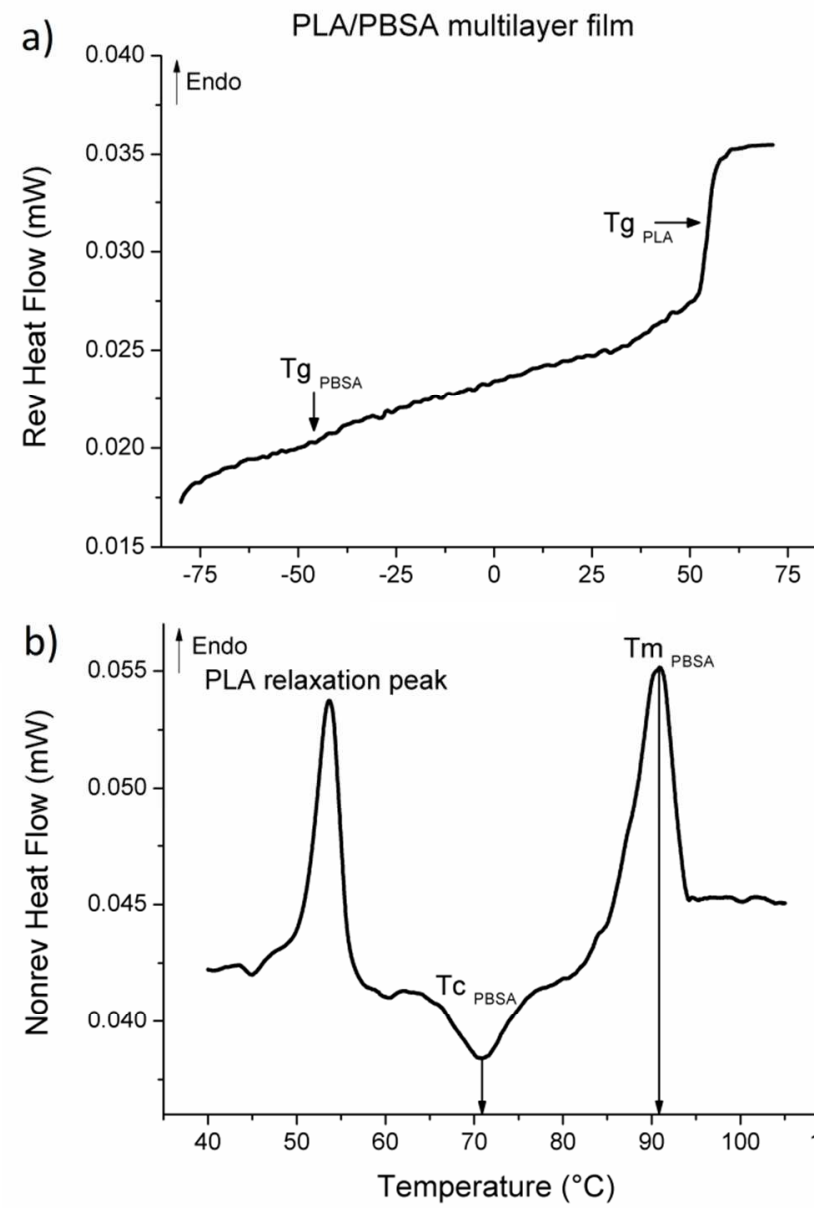

Figure 7. MT-DSC reversing and non-reversing heat flow curves for the multilayer film of PLA/PBSA showing a) the two glass transition temperatures $b$ ) the crystallization and melting temperatures of PBSA into the multilayer film. 
Table 2. Mechanical properties of the monolayer films of PLA and PBSA, and the multilayer film of PLA/PBSA.

\begin{tabular}{|c|c|c|c|}
\hline & Elastic modulus (MPa) & Yield stress (MPa) & Elongation at break (\%) \\
\hline PLA monolayer & $2141 \pm 89$ & $61 \pm 4$ & $8 \pm 2$ \\
\hline PBSA monolayer & $241 \pm 19$ & $17 \pm 1$ & $1360 \pm 148$ \\
\hline PLA/PBSA multilayer & $1723 \pm 79$ & $54 \pm 3$ & $37 \pm 10$ \\
\hline data from additivity law & 1761 & 52 & \\
\hline
\end{tabular}

Concerning the multilayer film, as shown by images of a multilayer PLA/PBSA sample (Figure 8) the absence of delamination during tensile tests and after breaking evidences the good quality in interfacial adhesion between the two immiscible polymers of the multilayer structure, indicating a rather good compatibility between both polyesters as well as a good homogeneity of the confined layers without any apparent defects and microvoids. In addition, the resulting elastic modulus and yield stress is relatively consistent with those calculated applying the additivity law based on the weight fractions of the two polymers. The adding of PBSA with PLA is particularly interesting because it improves the ductility of the PLA (elongation at break changed from 8 to $37 \%$ ) while keeping good stiffness and modulus of PLA.

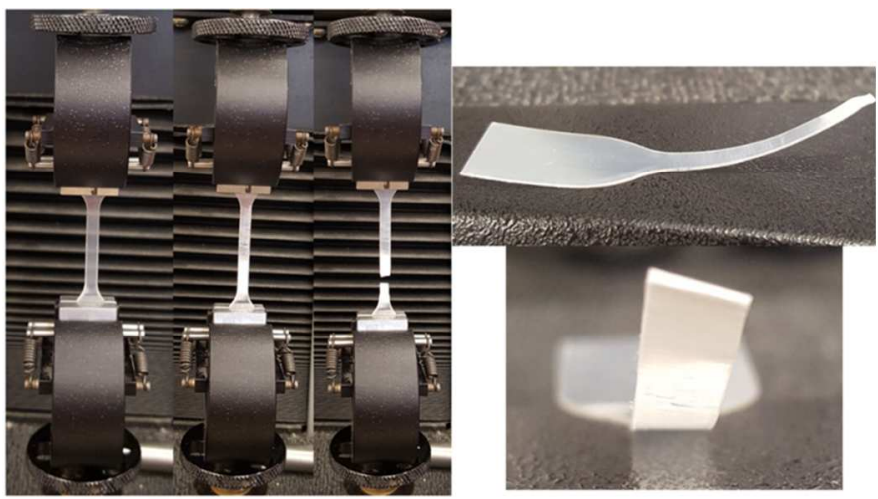

Figure 8. Images of the multilayer sample of PLA/PBSA during a tensile test and after breaking.

Barrier properties. The values of the permeability coefficients of the films towards gases $\left(\mathrm{N}_{2}, \mathrm{O}_{2}, \mathrm{CO}_{2}\right)$ and water vapor are gathered in Table 3 . The values of the monolayer films (Figure 9) are found to be similar to those reported for $\mathrm{PLA}^{43,44}$ and PBSA ${ }^{45}$ films. For example, oxygen permeation measurements on an amorphous PLA were carried out by Picard et al. ${ }^{46}$ and they have found a permeability coefficient and a diffusivity coefficient equal to 0.50 Barrer and $1.410^{-8}$ $\mathrm{cm}^{2} \cdot \mathrm{s}^{-1}$, respectively, which is close to the obtained values in this work.

Gas barrier properties. In first, despite the semi-crystalline structure of PBSA, it can be observed that the amorphous PLA film exhibits higher barrier properties, whatever the gas tested (Figure 9). This finding can be related to the fact that at the measurement temperature of $25{ }^{\circ} \mathrm{C}$, the amorphous PLA chains are at glassy state $\left(\mathrm{T}_{\mathrm{g}}=55^{\circ} \mathrm{C}\right)$, and hence without mobility, while the PBSA chains are at rubbery state $\left(\mathrm{T}_{\mathrm{g}}=-43\right.$ $\left.{ }^{\circ} \mathrm{C}\right)$. Furthermore, in that case, it is remarkable that the association of PBSA, as confined polymer, and PLA, as confining polymer, under a multilayer form results in better properties than the PLA film, except for $\mathrm{N}_{2}$ gas. Clearly the inherent continuous nanolayered structure and the decrease of PBSA permeability (see Table 3 , calculated $\mathrm{P}_{\mathrm{PBSA}}$ in the multilayer film) have strongly impacted the transport properties of PLA/PBSA film. This finding highlights structural changes induced by the continuous alternating between the amorphous PLA layers and the thin confined crystalline PBSA layers, and probably a certain densification of the PBSA amorphous phase by RAF increase.

The $\mathrm{P}_{\mathrm{N} 2}<\mathrm{P}_{\mathrm{O} 2}<\mathrm{P}_{\mathrm{CO} 2}$ ranking (Figure 9) observed for all films complies with the nature and diameter of gas molecules. ${ }^{47} \mathrm{CO}_{2}$ gas usually induces the highest permeability coefficient owing to its low kinetic diameter $(3.30 \AA)$ and higher critical temperature $\left(31.15^{\circ} \mathrm{C}\right)$. In contrast, the low critical temperature of $\mathrm{N}_{2}$ $\left(-146.94{ }^{\circ} \mathrm{C}\right)$, which has a higher dynamic diameter $(3.64 \AA)$ compared to oxygen $(3.46 \AA)$, explains the lowest permeability coefficient. 

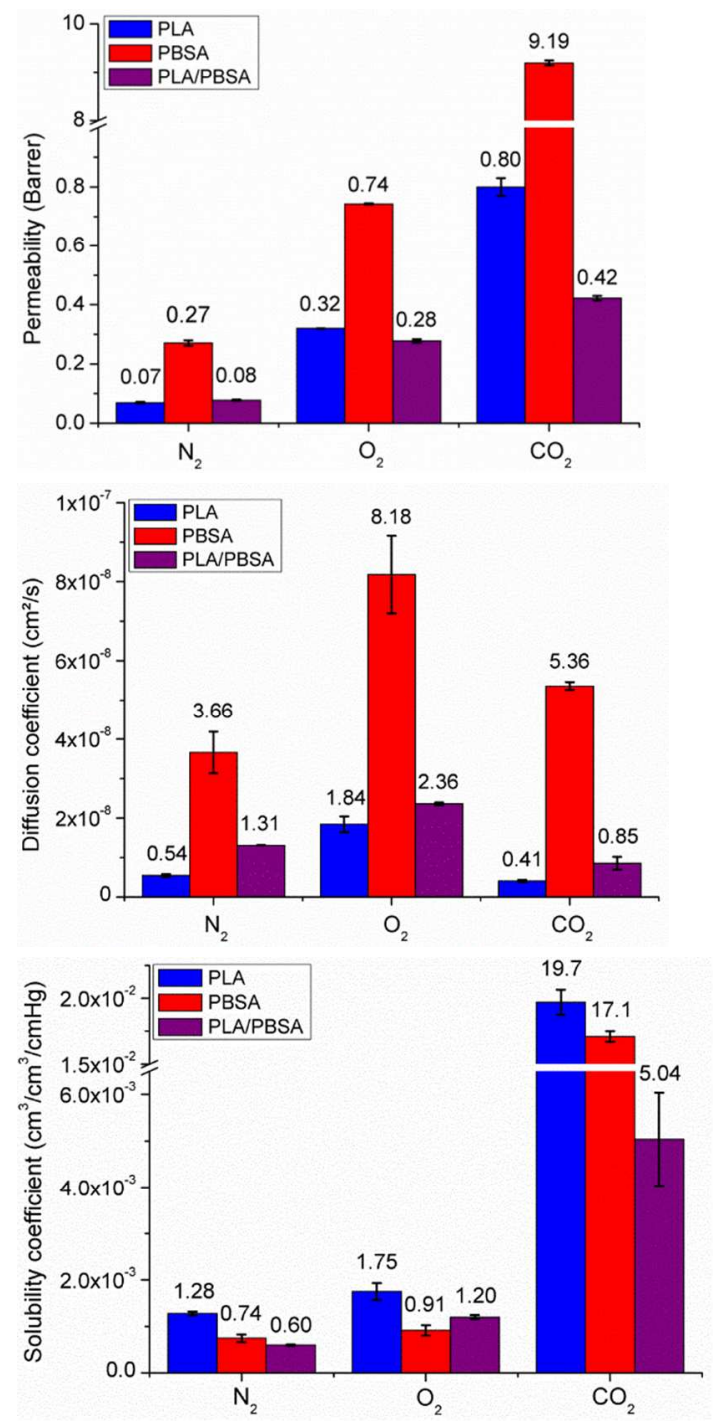

Figure 9. Gas permeability, diffusion and solubility coefficients for the monolayer films of PLA and PBSA and the multilayer film of PLA/PBSA.

Table 3. Gas and liquid water permeability coefficients for the monolayer films of PLA and PBSA and for the multilayer film of PLA/PBSA.

\begin{tabular}{|c|c|c|c|c|}
\hline & \multicolumn{4}{|c|}{ Permeability coefficient (in Barrer*) } \\
\hline & $\mathrm{N}_{2}$ & $\mathrm{O}_{2}$ & $\mathrm{CO}_{2}$ & $\mathrm{H}_{2} \mathrm{O}$ \\
\hline PLA monolayer & $0.069 \pm 0.003$ & $0.320 \pm 0.001$ & $0.80 \pm 0.03$ & $2510 \pm 124$ \\
\hline PBSA monolayer & $0.271 \pm 0.009$ & $0.743 \pm 0.002$ & $9.19 \pm 0.05$ & $8126 \pm 300$ \\
\hline PLA/PBSA multilayer & $0.078 \pm 0.002$ & $0.284 \pm 0.006$ & $0.422 \pm 0.008$ & $2049 \pm 19$ \\
\hline $\begin{array}{l}\text { Calculated permeability } P_{\mathrm{PLA} / \mathrm{PBSA}} \\
\text { (using eq. 6) }\end{array}$ & 0.081 & 0.361 & 0.982 & 2915 \\
\hline $\begin{array}{l}\text { Improvement Factor of the mul- } \\
\text { tilayer film PLA/PBSA }\end{array}$ & 1.0 & 1.3 & 2.3 & 1.4 \\
\hline $\begin{array}{l}\text { Calculated } P_{\mathrm{PBSA}} \text { in the multi- } \\
\text { layer film (using eq. } 7 \text { ) }\end{array}$ & 0.162 & 0.196 & 0.146 & 1186 \\
\hline $\begin{array}{l}\text { Improvement Factor of the con- } \\
\text { fined PBSA nanolayers }\end{array}$ & 1.7 & 3.8 & 62.9 & 6.9 \\
\hline
\end{tabular}

* 1 Barrer $=10^{-10} \mathrm{~cm}^{3}$ (STP) $\mathrm{cm} \mathrm{cm}^{-2} \mathrm{~s}^{-1} \mathrm{cmHg}^{-1}$ 
The gas permeability $P$ is driven by the dynamic diameter of gas as well as by their critical temperature through the diffusion coefficient $D$ related to gas mobility and the solubility coefficient $S$ relative to gas-polymer interactions, where $\mathrm{P}$ is expressed as $\mathrm{P}=\mathrm{D} \times \mathrm{S}$. The diffusivity $\mathrm{D}_{\mathrm{CO} 2}<\mathrm{D}_{\mathrm{N} 2}<\mathrm{D}_{\mathrm{O} 2}$ ranking (Figure 9), except for the PBSA film, was obtained and is in accordance with the decrease in the van der Waals volume of gas permeants $\left(\mathrm{V}_{\mathrm{CO} 2}=42.46>\mathrm{V}_{\mathrm{N} 2}=39.13>\mathrm{V}_{\mathrm{O} 2}=31.83\right.$ $\left.\mathrm{cm}^{3} \cdot \mathrm{mol}^{-1}\right)$. Such dependence is commonly reported in the literature. For the PBSA film, the fact that $\mathrm{D}_{\mathrm{CO} 2}>\mathrm{D}_{\mathrm{N} 2}$ is rather consistent with the dynamic diameter $\left(\phi_{\mathrm{CO} 2}=3.30<\phi_{\mathrm{N} 2}=\right.$ $3.64 \AA$ ). It seems that the molecular size of diffusing species differs between the amorphous state of PLA and the semicrystalline state of PBSA. In fact the gas permeation results do not make possible to say whether the amorphous state or the semi-crystalline state of the materials are at the origin of this behavior. As the diffusion of gas molecules can be correlated to the molecular size but considering two types of penetrant size means that the gas transport through PLA and PBSA is different. This discrepancy in diffusivity results would be linked to the structural differences between PLA and PBSA which lead to different ratio of available free volume in the material more or less accessible and depending on the mobility of segment chains, considering that the crystalline phase of PBSA brings tortuosity and can constrain some amorphous chains, the amorphous phase being in the rubbery state whereas the PLA is amorphous and in the glassy state.

For the solubility coefficient, the $\mathrm{S}_{\mathrm{N} 2}<\mathrm{S}_{\mathrm{O} 2}<\mathrm{S}_{\mathrm{CO} 2}$ ranking (Figure 9) follows the change in critical temperatures of gas permeants. Considering that crystals act as obstacles for diffusion and solubility, it is not surprising that the film of the semi-crystalline polymer (PBSA) presents lower solubility coefficients compared to the film of amorphous polymer (PLA), irrespective of gas molecules. Furthermore, with the increase in RAF, although the degree of crystallinity of $40 \%$ is equal to that of the PBSA film, one can note a large reduction in solubility for the multilayer film of PLA/PBSA. One can infer that the assembly of alternating layers with a semicrystalline polymer as confined layers hinders the gas solubility owing the creation of more rigid polymer chain area resulting from the micro-distortion of the chain packing during melt-processing leading to a certain localized densification. In others words, the reduction of the free volume and of mobility of some amorphous chains would be at the origin of the decrease of the gas solubility and consequently of the gas permeability. However, it must be reminded that there is no systematic correlation between stiffness and densification of the amorphous phase. It has been shown for example that the crystallization of PLA under its disordered crystalline form generates dedensified $\mathrm{RAF}^{48}$ that causes barrier properties to be equivalent or worse in comparison to amorphous PLA. ${ }^{49,50}$ It is worth mentioning that our hypothesis of amorphous phase densification is consistent with the variations of solubility coefficient, yet needs experimental evidences, by positron annihilation lifetime spectroscopy for example.

When compared to the calculated permeability values using the series model, the gas barrier improvement of PLA/PBSA multinanolayer films deduced would be mainly due to the reduction of the solubility rather than of the diffusivity (Figure 9). It seems that the times of diffusion are not so much increased as it could be expected if we consider the reduction of chain segment mobility, the constrained amorphous chains in RAF and so the densification increase in the confined layers. By studying the transport properties of PBSA films prepared by compression-molding or extrusion process, Charlon et $\mathrm{al}^{22}$ have shown that the amount of RAF did not significantly increase the tortuosity because of the size of the RAF which is generally considered to be small in comparison with the adjacent crystalline and MAF phases. Moreover, their results of gas permeation have clearly demonstrated that by increasing the RAF of PBSA films with the extrusion process in comparison with the compression-molding, the $\mathrm{O}_{2}$ and $\mathrm{CO}_{2}$ barrier properties were improved and this was mainly due to the reduction of the gas solubility. These correlations between RAF and gas solubility reduction are really consistent with our results.

Water vapor barrier properties. To overcome the effect related to the film thickness, the water permeation kinetics were corrected using the reduced scale J.L $=f\left(t / L^{2}\right)$. As shown in Figure $10 \mathrm{a}$, the water permeation flux as a function of the reduced time, is faster for the PBSA film until a higher constant value at steady state is measured (the water permeability coefficient is accordingly calculated at the stationary state). This finding is again related to the glassy/rubbery state of polymers at the measurement temperature. Considering the steady state of the water permeation, the permeation flux of the multilayer film is lower than those of the two monolayer films. This result clearly attests for an improvement of the barrier properties of the semi-crystalline PBSA polymer when prepared in multilayer form mainly because of its confinement by the PLA layers which allows to increase the RAF percent and to modify the local density of the amorphous phase by reducing the free volume. 

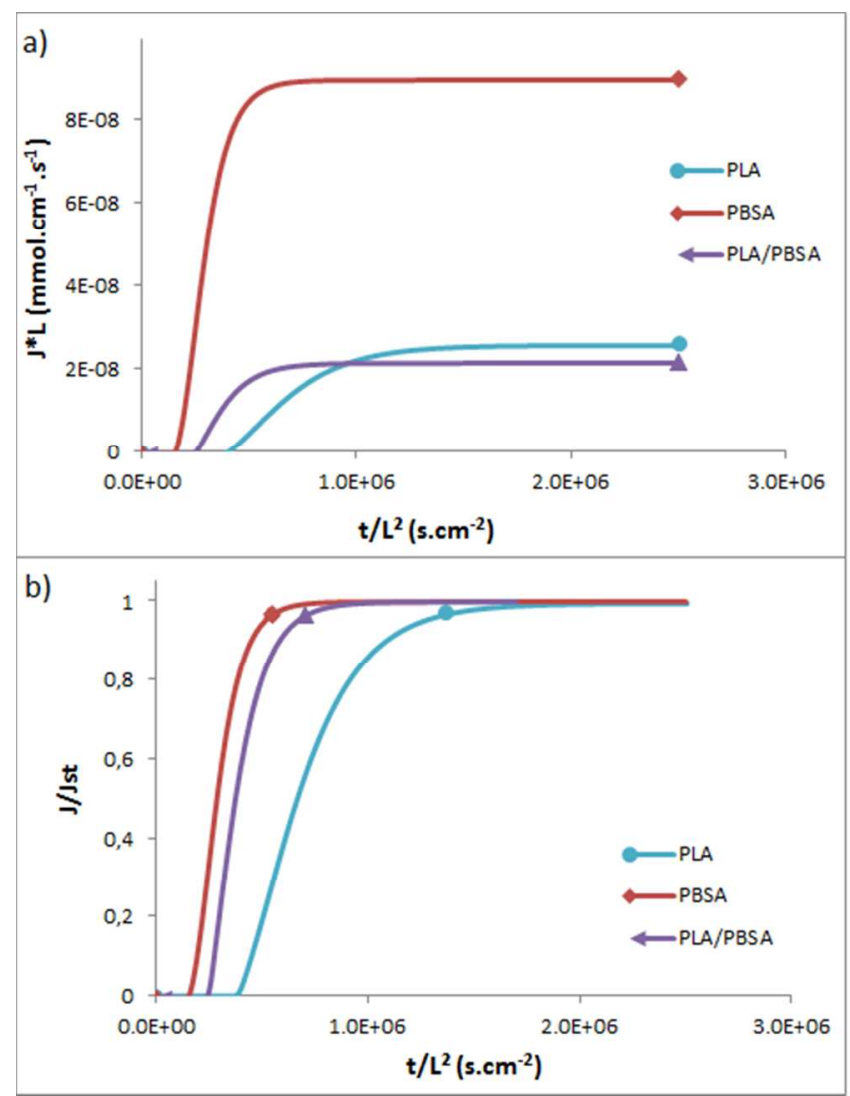

Figure 10. a) Reduced and b) normalized water permeation curves as a function of the reduced time for the monolayer films of PLA and PBSA and the multilayer film of PLA/PBSA.

From the normalized water permeation curves as a function of the reduced time (see Figure 10b), one can note a slight increase in the delay time in diffusion of the flux curve for the multilayer film compared to the PBSA film but at the same time a faster time in diffusion compared to the PLA film, indicating that tortuosity effects expected due to possible alignment and micro-distortion of PBSA crystals within the confined layers are not so strong. This is confirmed by the $D_{0}$ values, which is commonly determined from the slope of the curve. These results are in good agreement with those of gas permeation highlighting much more effect resulting from the solubility than from the diffusivity.

Unlike gas molecules, water usually induces a plasticization effect and the dependence of the water diffusivity on the water concentration is usually described through an exponential law, that is $D=D_{0} e^{\gamma C} .^{51}$ The analysis of this law was already used to fit well the water permeation flux of PLA ${ }^{52}$ and PBSA. ${ }^{36}$ From data of Table 4 , as $\mathrm{D}_{0}<\mathrm{D}_{\mathrm{M}}$ (the maximum diffusion coefficient, Eq.10), it means that the water-induced plasticization occur for the multilayer film, and also for the two monolayer films. However, the water concentration $C_{e q}$ at the equilibrium state (steady state) within the multilayer film of PLA/PBSA is clearly lower than those of the two reference films, indicating a limitation in the water concentration attributable to the formation of thin PBSA layers and to a reduction in chain mobility by RAF formation. Again this result agrees well with the reduction of solubility that may be caused by the reduction of the free volume due to the densification increase in the confined layers.

Table 4. Water permeation parameters for the monolayer films of PLA and PBSA and the multilayer film of PLA/PBSA.

\begin{tabular}{|l|l|l|l|l|l|l|}
\hline & $\mathrm{P}($ Barrer $)$ & $\begin{array}{l}\mathrm{D}_{0} \\
\left(10^{-8} \mathrm{~cm}^{2} \cdot \mathrm{s}^{-1}\right)\end{array}$ & $\begin{array}{l}\mathrm{D}_{\mathrm{M}} \\
\left(10^{-8} \mathrm{~cm}^{2} \cdot \mathrm{s}^{-1}\right)\end{array}$ & $\gamma \mathrm{C}_{\mathrm{eq}}$ & $\begin{array}{l}\gamma \\
\left(\mathrm{cm}^{3} \cdot \mathrm{mmol}^{-1}\right)\end{array}$ & $\begin{array}{l}\mathrm{C}_{\mathrm{eq}} \\
\left(\mathrm{mmol}_{\mathrm{cm}} \mathrm{cm}^{-3}\right)\end{array}$ \\
\hline PLA monolayer & $2510 \pm 124$ & $0.87 \pm 0.07$ & $11.6 \pm 0.7$ & $2.6 \pm 0.2$ & $4.0 \pm 0.1$ & $0.67 \pm 0.03$ \\
\hline PBSA monolayer & $8126 \pm 300$ & $2.0 \pm 0.5$ & $26.0 \pm 8.0$ & $2.6 \pm 0.6$ & $2.8 \pm 1.0$ & $0.90 \pm 0.10$ \\
\hline PLA/PBSA multilayer & $2049 \pm 19$ & $1.1 \pm 0.1$ & $20.0 \pm 5.0$ & $2.9 \pm 0.2$ & $8.6 \pm 2.0$ & $0.34 \pm 0.06$ \\
\hline
\end{tabular}


Improvement factor. The predicted permeability of a film composed of PLA and PBSA at a 80:20 ratio was determined using the equation 8 based on the experimental permeability coefficients of the monolayer films paired with the volume fractions. One can note that the calculated values are always higher than the measured values, irrespective of permeants (Table 3). This result is a theoretical approach to outline the effect of the nanolayer processing inducing nanoconfinement.

Second, to highlight the improvement of barrier properties, the permeability coefficient of the PBSA layers within the multilayer film was extracted from the series model (see eq. 7) and is further compared to the experimental value for the monolayer film of PBSA. The calculated permeability $P_{\mathrm{PBSA}}$ in the multilayer film of PLA/PBSA was then determined by:

$$
P_{\mathrm{PBSA}}=\frac{\varphi_{\mathrm{PBSA}}}{\frac{1}{P_{\mathrm{Film}}}-\frac{\varphi_{\mathrm{PLA}}}{P_{\mathrm{PLA}}}}
$$

From Table 3, one can point out that the calculated permeability $P_{\mathrm{PBSA}}$ is very significantly lower to the experimental permeability of the reference film, whatever the permeant, showing structural changes due to confinement effect in PBSA layers during the melt-coextrusion processing and that explains the improvement in barrier properties. The transfer of permeants through the multilayer film is as a result limited by the RAF formation, by the densification of the RAF when the PBSA was under multilayer form and probably by a reduction of the free volume obtained by the confinement effect. This influence on the permeant transfer can be highlighted by the improvement factor which was determined by the ratio of the permeability of PBSA in the monolayer film to the permeability of the PBSA into the multilayer film. The results given in Table 3 are graphically represented in Figure 11.

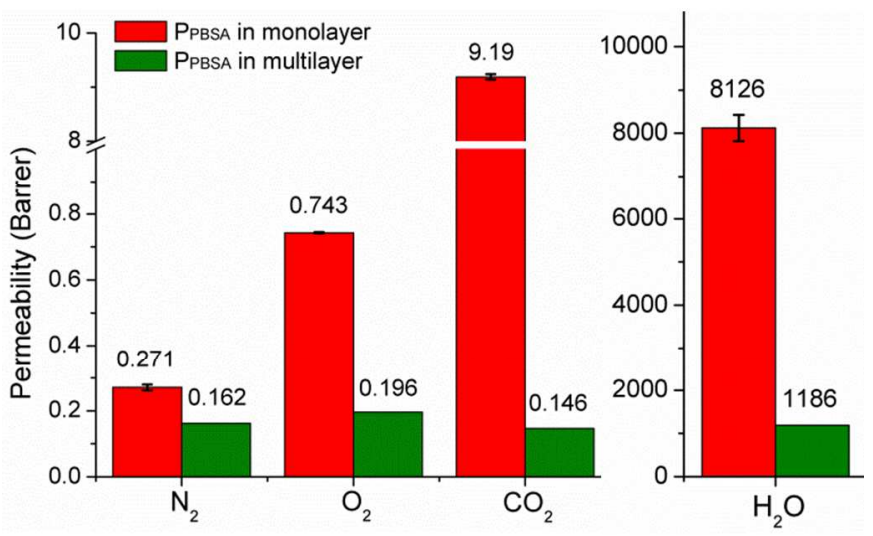

Figure 11. Graphical representation of the improvement of PBSA barrier properties.

The best improvement factor, i.e. the best decreasing of permeability, is obtained with water and $\mathrm{CO}_{2}$ with 7 and 63 of improvement, respectively. It emerges that the best improvement converges to a two-decade increase in the latter case. On the other hand, we can note that the difference between the PBSA permeability value in the monolayer and the PBSA permeability value calculated in the multilayer is much lower for $\mathrm{N}_{2}$ with respect to $\mathrm{O}_{2}, \mathrm{CO}_{2}$ and $\mathrm{H}_{2} \mathrm{O}$. First, the fact that the barrier improvement is not the same for all gases is not surprising and generally observed in most cases such as for nanocomposite materials. Besides, it can be observed for the same material a barrier improvement to some permeants while the permeability for other permeants can be highly increased, as shown for PHBV based nanocomposites. ${ }^{53}$ These differences in barrier effect between gases or vapors are usually interpreted taking into account kinetic (tortuosity effect) and thermodynamic (interaction) aspects. In our case, we infer that the lower barrier effect for $\mathrm{N}_{2}$ would be due to its lower capacity to be dissolved in comparison with other penetrants. Indeed, by considering that the barrier improvement is mainly due to the reduction of solubility, it is expected that the reduction of free volume would impact much more molecules having higher condensability and that is the case especially for $\mathrm{CO}_{2}$. Thus the constrained amorphous chains in RAF located at the crystal/amorphous interface but also the densification of the amorphous chains induced by the confinement effect would participate to the decrease of the fraction of the free volume in the multilayer leading to strongly reduce the ability of gas molecules to be dissolved in the confined layers. This is all the more pronounced as the molecule is condensable.

In a general way, in the PLA/PBSA multilayer, as the crystallinity was not modified, the small orientation of the crystals, the decrease of the free volume linked to the densification increase and the increase of constrained chains in the confined nanolayers allowed to interpret the barrier effects for gas and water.

\section{CONCLUSIONS}

Nowadays, faced with a competitive market of packaging which requires more eco-friendly materials of high performances such as strong barrier properties, we have developed innovative biodegradable multi-nanolayer films by using nanolayer processing based on forced assembly of two biodegradable polymers: PLA and PBSA. A two-decades improvement of $\mathrm{CO}_{2}$ barrier properties were obtained for the confined PBSA. Such an improvement results from the structural change induced by the confinement effect in the PBSA nanolayers and leading to a slight orientation of the crystals, an increase of the rigid amorphous fraction percent for the PBSA and its probable densification as revealed by the decrease of the solubility coefficient for the multilayer film. Considering that the enhancement of the barrier properties can be due to concomitant effects (densification, reduction of chain segment mobility, orientation of amorphous chains, increase of tortuosity), it will be very interesting to quantify the decrease of the free volume in the multilayer structure, however its determination by positron annihilation lifetime spectroscopy (PALS) could be quite difficult because of the complex structure of this multilayer which contains alternating semi-crystalline layers.

The confinement of PBSA, though less barrier than PLA, by multilayer coextrusion processing were performed without polymer interdiffusion and with a good layer integrity. The resulting biodegradable multi-nanolayer film was found to be more barrier and ductile than a film made solely of PLA while keeping its good stiffness, in opposition to a classical multilayer film. It can be noted that this improvement was induced 
by the presence of only $20 \mathrm{wt} \%$ PBSA that shows at which point the confinement effect can play an important role. Furthermore, in spite of the opacity of PBSA, we have successfully kept the transparency of PLA in the multilayer film, which is a key parameter for a future industrial use as the ductility plays also an important role. financial support of the PhD fellowship of T. Messin. The authors thank also the Region Nord-Pas-de-Calais and the European Regional Development Fund (ERDF) for funding contribution to the X-ray equipment.
TOC

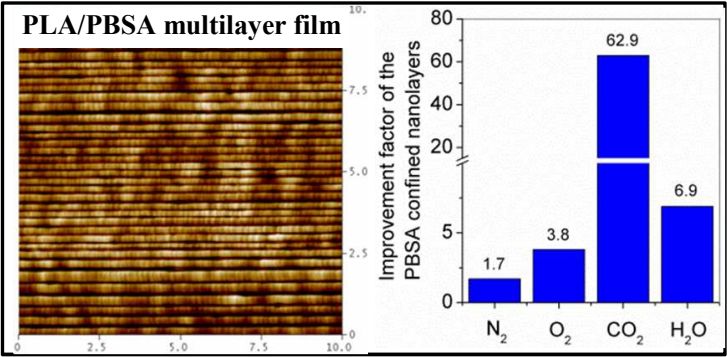

\section{AUTHOR INFORMATION}

\section{Corresponding Author}

* e-mail: stephane.marais@univ-rouen.fr

* e-mail: nadege.follain@univ-rouen.fr

\section{Author Contributions}

The manuscript was written through contributions of all authors given approval to the final version of the manuscript.

\section{ACKNOWLEDGMENT}

The authors thank the GRR Crunch under Grant No. EOTP $\mathrm{N}^{\circ} 427341$ (supported by Upper Normandy region, France) for the

1 Schrenk, W. J. Method for multilayer coextrusion. Google Patents 1973.

2 Schrenk, W. J.; Bradley, N. L.; Alfrey, Jr. T.; Maack, H. Interfacial Flow Instability in Multilayer Coextrusion. Polym. Eng. Sci. 1978, 18, 620-623.

3 Ponting, M.; Hiltner, A.; Baer, E. Polymer Nanostructured by Forced Assembly: Process, Structure, and Properties. Macromol. Symp. 2010, 294-1, 19-32.

4 Kazmierczak, T.; Song, H.; Hiltner, A.; Baer, E. Polymeric One-dimensional Photonic Crystals by Continuous Coextrusion. Macromol. Rapid Commun. 2007, 28, 2210-2216.

5 Ebeling, T.; Hiltner, A.; Baer, E. Delamination Failure Mechanisms in Microlayers of Polycarbonate and Poly(styrene-co-acrylonitrile). J. Appl. Polym. Sci. 1998, 68, 793-805.

6 Kerns, J.; Hsieh, A.; Hiltner, A.; Baer, E. Mechanical Behavior of Polymer Microlayers. Macromol. Symp. 1999, 174, 15-25.

7 Jordan, A. M.; Lenart, W. R.; Carr ,J. M.; Baer, E.; Korley, T. J. Structural Evolution During Mechanical Deformation in High-barrier PVDFTFE/PET Multilayer Films Using in situ X-ray Techniques. ACS Appli. Mater. Interfaces 2014, 6, 3987-3934.

8 Lin, Y.; Hiltner, A.; Baer, E. A New Method for Achieving Nanoscale Reinforcement of Biaxially Oriented Polypropylene Film. Polymer $2010,51,4218-4224$.

9 Wang, H.; Keum, J.K.; Hiltner, A.; Baer, E.; Freeman, B.; Rozanski, A.; Galeski, A. Confined Crystallization of Polyethylene Oxide in Nanolayer Assemblies. Science 2009, 323, 757-760.

10 Zhang, G.; Lee, P.C.; Jenkins, S.; Dooley, J.; Baer, E. The Effect of Confined Spherulite Morphology of High-density Polyethylene and Polypropylene on Their Gas Barrier Properties in Multilayered Film Systems. Polymer 2014, 55, 4521-4530.

11 Boufarguine, M.; Guinault, A.; Miquelard-Garnier, G.; Sollogoub, C. PLA/PHBV Films with Improved Mechanical and Gas Barrier Properties. Macromol. Mater. Eng. 2013, 298, 1065-1073.

12 Miquelard-Garnier, G.; Guinault, A.; Fromonteil, D.; Delalande, S.; Sollogoub, C. Dispersion of Carbon Nanotube in Polypropylene via Multilayer Coextrusion: Influence on the Mechanical Properties. Polymer 2013, 54, 4290-4297.

13 Li, X.; Miquelard-Garnier, G.; Guinault, A.; Sollogoub, C.; Regnier, G.; Rozanski, A. Force Assembly by Multilayer Coextrusion to Create Oriented Graphene Reinforced Polymer Nanocomposites, Polymer 2013, 55, 248-257.

14 Roland, S.; Miquelard-Garnier, G.; Gervais, M.; Guinault, A.; Sollogoub, C. Controlling the Order of Triblock Copolymer via Confinement Induced by Forced Self-assembly. Mater. Today Commun. 2016, 6, 37-43.

15 Carr, J.M.; Langhe, D.S.; Ponting, M.T.; Hiltner, A.; Baer, E. Confined Crystallization in Polymer Nanolayered Films: A review. J. Mater. Res. 2012, 27, 1326-1350 
16 Wang, H.P.; Keum, J.K.; Hiltner, A.; Baer, E. Crystallization Kinetics of Poly(ethylene oxide) in Confined Nanolayers. Macromolecules 2010, 43, 3359-3364.

17 Ponting, M.; Lin, Y.; Keum, J.K.; Hiltner, A.; Baer, E. Effect of Substrate on the Isothermal Crystallization Kinetics of Confined Poly( $\varepsilon-$ caprolactone) Nanolayers. Macromolecules 2010, 43, 8619-8627.

18 Lai, C.Y.; Hiltner, A.; Baer, E.; Korley, L.T.J. Deformation of Confined Poly(ethylene oxide) in Multilayer Films. ACS Appl. Mater. Interfaces 2012, 4, 2218-2227.

19 Lin, Y.; Hiltner, A.; Baer, E. Nanolayer Enhancement of Biaxially Oriented Polypropylene Film for Increased Gas Barrier. Polymer 2010, $51,5807-5814$.

20 Lin, Y.; Hiltner, A.; Baer, E. A New Method for Achieving Nanoscale Reinforcement of Biaxially Oriented Polypropylene Film. Polymer 2010, 51, 4218-4224.

21 Esposito, A.; Delpouve, N.; Causin, V.; Dhotel, A.; Delbreilh, L.; Dargent, E. From a Three-phase Model to a Continuous Description of Molecular Mobility in Semicrystalline Poly(hydroxybutyrate-co-hydroxyvalerate). Macromolecules 2016, 49, 4850-4861.

22 Charlon, S.; Marais, S.; Dargent, E.; Soulestin, J.; Sclavons, M.; Follain, N. Structure-Barrier Property Relationship of Biodegradable Poly(butylene succinate) and Poly[(butylene succinate)-co-(butylene adipate)] Nanocomposites: Influence of the Rigid Amorphous Fraction. Phys. Chem. Chem. Phys. 2015, 17, 29918-29934.

23 Duan, Z.; Thomas, N.L.; Huang, W. Water Vapour Permeability of Poly(lactic acid) Nanocomposites. J. Memb. Sci. 2013, 445, 112-118.

24 Lai, S.M.; Hsieh, Y.T. Preparation and Properties of Polylactic acid (PLA)/Silica Nanocomposites. J. Macromol. Sci. Part B Phys. 2016, 55, 211-228.

25 Nikolic, M.S.; Djonlagic, J. Synthesis and Characterization of Biodegradable Poly(butylene succinate-co-butylene adipate)s. Polym. Degrad. Stab. 2001, 74, 263-270.

26 Ahn, B.D.; Kim, S.H.; Kim, Y.H.; Yang, J.S. Synthesis and Characterization of Biodegradable Copolymers from Succinic Acid and Adipic Acid with 1,4-butanediol. J. Appl. Polym. Sci. 2001, 82, 2808-2826.

27 Bandyopadhyay, J.; Al-Thabaiti, S.A.; Ray, S.S.; Basahel, S.N.; Mokhtar, M. Unique Cold-Crystallization Behavior and Kinetics of Biodegradable poly[(butylene succinate)-co adipate] Nanocomposites: a High Speed Differential Scanning Calorimetry Study. Macromol. Mater. Eng. 2014, 299, 939-952.

28 Messin, T.; Follain, N.; Guinault, A.; Miquelard-Garnier, G.; Sollogoub, C.; Delpouve, N.; Gaucher, V.; Marais, S. Confinement Effect in PC/MXD6 Multilayer Films: Impact of the Microlayered Structure on Water and Gas Barrier Properties. J. Memb. Sci. 2017 , 525, 135-145.

29 Gupta, M.; Lin, Y.; Deans, T.; Baer, E.; Hiltner, A.; Schiraldi, D.A. Structure and Gas Barrier Properties of Poly(propylene-graft-maleic anhydride)/Phosphate Glass Composites Prepared by Microlayer Coextrusion. Macromolecules 2010, 43, 4230-4239.

30 Prattipati, V.; Hu, Y.S.; Bandi, S.; Schiraldi, D.A.; Hiltner, A.; Baer, E.; Mehta, S.; Effect of Compatibilization on the Oxygen-Barrier Properties of Poly(ethylene terephthalate)/Poly(m-xylylene adipamide) Blends. J. Appl. Polym. Sci. 2005, 97, 1361-1370.

31 Wang, H.; Keum, J.K.; Hiltner, A.; Baer, E. Confined Crystallization of PEO in Nanolayered Films Impacting Structure and Oxygen Permeability. Macromolecules 2009, 42, 7055-7066.

32 Kumins, C.A.; Kwei, T.K.; in Diffusion in Polymers, Crank, J.; Park, G. S.; Eds. Academic Press New York 1968, $135-137$.

33 Mackey, M.; Flandin, L.; Hiltner, A.; Baer, E. Confined Crystallization of PVDF and a PVDF-TFE Copolymer in Nanolayered Films. J. Polym. Sci. Part B Polym. Phys. 2011, 49, 1750-1761.

34 Bironeau, A.; Dirrenberger, J.; Sollogoub, C.; Miquelard-Garnier, G.; Roland, S. Evaluation of Morphological Representative Sample Sizes for Nanolayered Polymer Blends, J. Microsc. 2016, 0, 1-11.

35 Ray, S.S.; Bousmina, M.; Okamoto, K. Structure and Properties of Nanocomposites Based on Poly(butylene succinate-co-adipate) and Organically Modified Montmorillonite. Macromol. Mater. Eng. 2005, 290, 759-768.

36 Charlon, S.; Follain, N.; Chappey, C.; Dargent, E.; Soulestin, J.; Sclavons, M.; Marais, S. Improvement of Barrier Properties of Bio-based Polyester Nanocomposite Membranes by Water-assisted Extrusion. J. Memb. Sci. 2015, 496, 185-198.

37 Makhatha, M.E.; Ray, S.S.; Hato, J.; Luyt, A.S. Thermal and Thermomechanical Properties of Poly(butylene succinate) Nanocomposites. J. Nanosci. Nanotechnol. 2008, 8, 1679-1689.

38 Ray, S.S.; Bandyopadhyay, J.; Bousmina, M. Thermal an Thermomechanical Properties of Poly[(butylene succinate)-co-adipate] Nanocomposite. Polym. Degrad. Stab. 2007, 92, 802-812.

39 Rhim, J.W.; Hong, S.I.; Ha, C.S. Tensile, Water Vapor Barrier and Antimicrobial Properties of PLA/Nanoclay Composite Films. Food Sci. Technol. 2009, 42, 612-617.

40 Mallet, B.; Lamnawar, K.; Maazouz, A. Improvement of Blown Film Extrusion of Poly(lactic acid): Structure-Processing-Properties Relationships. Polym. Eng. Sci. 2013, 54, 840-857.

41 Zhang, X.; Zhang, Y. Poly(butylene succinate-co-butylene adipate)/Cellulose Nanocrystal Composites Modifies with Phthalic Anhydride. Carbohydrate Polymers 2015, 134, 52-59.

42 Ratto, J.A.; Stenhouse, P.J.; Auerbach, M.; Mitchell, J.; Farrell, R. Processing, Performance and Biodegradability of a Thermoplastic Aliphatic Polyester/Starch System. Polymer 1999, 40, 6777-6788.

43 Bao, L.; Dorgan, J. R.; Knauss, D.; Hait, S.; Oliveira, N. S.; Maruccho, I. M. Gas Permeation Properties of Poly(lactic acid) Revisited. J. Memb. Sci. 2006, 285, 166-172.

44 Komatsuka, T.; Kusakabe, A.; Nagai, K. Characterization and Gas Transport Properties of Poly(lactic acid) Blend Membranes. Desalination $2008,234,212-220$

45 Charlon, S.; Follain, N.; Dargent, E.; Soulestin, J.; Sclavons, M.; Marais, S. Poly[(butylene succinate)-co-(butylene adipate)]Montmorillonite Nanocomposite Prepared by Water-assisted Extrusion: Role of the Dispersion Level and of the Structure-Microstructure on the Enhanced Barrier Properties. J. Phys. Chem. 2016, 120, 13234-13248.

46 Picard, E.; Espuche, E.; Fulchiron, R. Effect of an Organo-modified Montmorillonite on PLA Crystallization and Gas Barrier Properties. Appl. Clay. Sci. 2011, 53, 58-65.

47 Van Krevelen, D.W. Properties of Polymers. Elsevier, Amsterdam Oxford 3rd edition, 1990.

48 Del Rio, J.; Etxeberria, A.; López-Rodríguez, N.; Lizundia, E.; Sarasua, J.R. A PALS Contribution to the Supramolecular Structure of Poly(L-lactide). Macromolecules 2010, 43, 4698-4707. 
49 Guinault, A.; Sollogoub, C.; Ducruet, V.; Domenek, S. Impact of Crystallinity of Poly(lactide) on Helium and Oxygen Properties. Eur. Polym. J. 2012, 48, 779-788.

50 Fernandes Nassar, S.; Guinault, A.; Delpouve, N.; Divry, V.; Ducruet, V.; Sollogoub, C.; Domenek, S. Multi-scale Analysis of the Impact of Polylactide Morphology on Gas Barrier Properties. Polymer 2017, 108, 163-172.

51 Follain, N.; Valleton, J.M.; Lebrun, L.; Alexandre, B.; Schaetzel, P.; Metayer, M.; Marais, S. Simulation of Kinetic Curves in Mass Transfer Phenomena for a Concentration-Dependent Diffusion Coefficient in Polymer Membranes. J. Memb. Sci. 2010, 349, 195-207.

52 Tenn, N.; Follain, N.; Fatyeyeva, K.; Poncin-Epaillard, F.; Labrugère, C.; Marais, S. Impact of Hydrophobic Plasma Treatments on the Barrier Properties of Ply(lactic acid) Films. RSC Adv. 2014, 4, 5626-5637.

53 Crétois, R.; Follain, N.; Dargent, E.; Soulestin, J.; Bourbigot, S.; Marais, S. Microstructure and Barrier Properties of PHBV/Organoclays Bionanocomosites. J. Memb. Sci. 2014, 467, 56-66. 